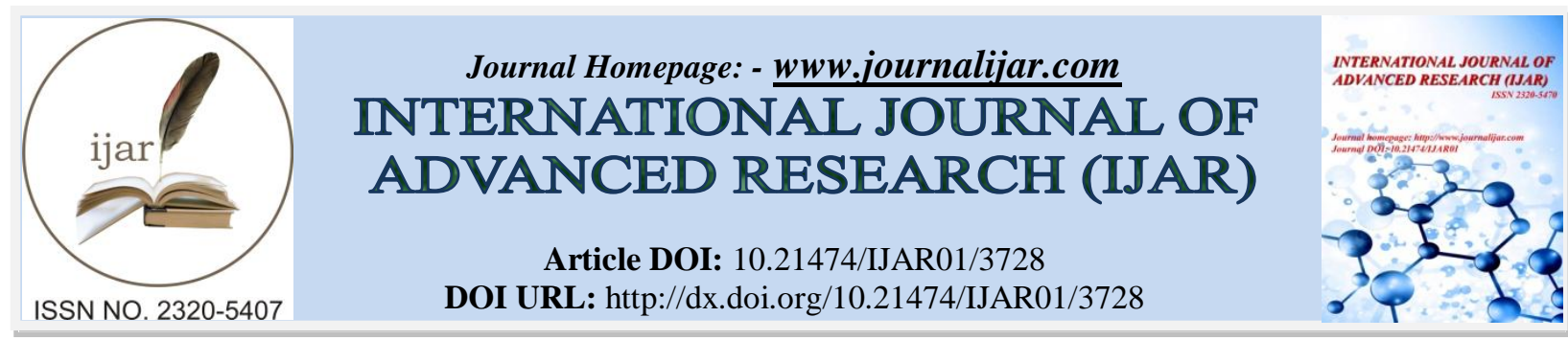

RESEARCH ARTICLE

\title{
CANTILEVER BEAM-LIKE DESIGN OF RC RETAINING WALL WITH MULTIPLE PRESSURE RELIEF SHELVES AND ELASTIC FOUNDATION.
}

Umit Gokkus ${ }^{1 *}$ and Yesim Tuskan ${ }^{2}$.

1. Professor, Department of Civil Engineering, Celal Bayar University, Izmir, Turkey, 450140 Manisa/Turkey.

2. Res.Asst.(M.Sc),Department of Civil Eng, Celal Bayar University,Izmir/Turkey.

\section{Manuscript Info}

Manuscript History

Received: 15 January 2017

Final Accepted: 03 February 2017

Published: March 2017

Key words:-

Cantilever-Beamlike Retaining Wall, Relief Shelf in Retaining Wall,

Stepwise and Multi-Row Steel Bar

Design, Rankine 's Lateral Active Earth

Pressure

\begin{abstract}
In this study the magnitude of reduction in total active earth pressure, overturning moments at the bottom of the wall and its distribution due to the response of a relief shelf in a retaining wall is presented with cantilever type retaining wall on cohesionless soils with increase of additional resisting moments at the bottom of the wall. Retaining wall is considered as cantilever beam-like, multi-rows and stepwise reinforced concrete, multi-shelves on vertical wall and elastic foundation. A numerical study is conducted to investigate the effect of the number of shelves; shelf and wall stem rigidity and shelf horizontal location on the resulted lateral earth pressure distribution. Pressure quantity, the maximum acting bending moment and shear force on the wall are also discussed to perform the retaining design. Currently, numerical analysis is one of the easiest and the fastest method to examine the effect of each factor on the dynamic behavior of a retaining wall. According to the analysis it was found that the shelves have a significant effect on the distribution of the earth pressure. The numerical results indicate that the presence of a relief shelf behind the wall would result in a reduction of the earth pressure and also results show that shelf inclusions have positive role as pressure detractive for cantilever retaining walls in earthquake areas.
\end{abstract}

Copy Right, IJAR, 2017,. All rights reserved.

\section{Introduction:-}

A retaining wall will be subjected to an additional load under the seismic and wave conditions and caused not only by the dynamic lateral earth pressure and wave force but also by the inertial force due to the structural mass reduced by pressure relief shelves. The lateral force acting between the retaining structure and the backfill mass is termed as lateral earth pressure. Cantilever retaining walls with pressure relief shelves are considered one special subset of retaining walls (Farouk,2015). The concept of providing pressure relief shelves towards the active soil mass side of a retaining wall reduces the total earth pressure on the wall, which results in reducing the thickness of the wall and ultimately to get an economic design by use of less reinforcement on wall horizontal cross section on the level of contraction joints (Farouk,2015). Over the decades, several types of methods have been developed to calculate the complex dynamic soil interactions between a retaining wall and retained earth mass. These methods can be categorized into limit state analyses, closed form solutions, numerical analyses, and experimental methods (Padhye,2011). Jumikis (1964) presented the provision of one or more relief shelves to increase the stability of retaining wall. The relief shelves have an advantage of decreasing the overall lateral earth pressure on the structure. 
An economical design is reached because of less material use in construction mechanism as compared to massive structure of cantilever retaining walls without shelves (Jumukis,1964). Chaudhury (1973) proposed Coulomb's theory for earth pressure computation for cohesionless soil. He presented the charts for various locations and widths of relief shelf. and compared cantilever and counterfort type retaining wall in reinforced concrete with and without relief shelf to show the economy in providing a relief shelf (Chaudhury,1964). According to Phatak (1975) the effect of relief shelves can increase the stability of retaining wall by using the Rankine's theory to evaluate the lateral pressures (Phatak,1975). He presented experimental study on flexible cantilever wall with relief shelf to show substantial reduction in earth pressure (Phatak,1975). In order to facilate the reduction of earth pressure and increase stability against sliding and overturning, construction of relief shelves behind retaining wall was used (Banerjee,1977). Padhye and Ullagaddi (2011) presented the procuration of one or more relief shelves to increase and to provide the stability of retaining wall. They considerably applied Coulomb's theory for analysis and design of cantilever type of wall for cohesionless soil (Padhye,2011).

In this study, RC retaining wall to provide both of lower overturning moments caused by decreasing lateral active earth pressure forces and lower opposing bending moments originated from gravity weights of shelves are analytically analyzed on elastic foundation. Special retaining wall is designed and analyzed holistically under the conditions such as cantilever beamlike vertical section, doubly reinforced rectangular base sectionon elastic foundations and vertical wall with multi-shelf, stepwise and three-rows reinforcement.

\section{Methodology:-}

The retaining wall is designed against sliding and overturning using Rankin's earth pressure theory based on stress equilibrium of a soil mass element. The method of Rankine is still the most widely used to compute earth active thrusts on walls. For the wall geometry and ground conditions considered on this study, wall movements are reduced more effectively by providing multiple relief shelf than increasing the wall's base slab, at least if the wall's bending moment and stability remains unchanged. This paper deals mainly with seismic considerations. The stability of retaining wall checked to ensure that it is capable of supporting the design lateral forces. The stability regulations require that the selected retaining wall cast on the case study satisfy requirements for sliding, overturning and bearing capacity. The relationship between principal stresses when the soil reaches a state of plastic equilibrium can be derived from Mohr circle with a failure plane at an angle of $45+\phi^{\prime} / 2$.

The active pressure coefficient is has been proposed by Rankine's theory as (Kip et al.1999)

$$
K_{a}=\cos \alpha \frac{\cos \alpha-\sqrt{\cos ^{2} \alpha-\cos ^{2} \emptyset^{\prime}}}{\cos \alpha+\sqrt{\cos ^{2} \alpha-\cos ^{2} \varnothing^{\prime}}}
$$

Where $\alpha$ is an inclination angle with the horizontal surface and $\varnothing^{\prime}$ is internal friction angle of soil. The horizontal stress for the above condition is defined as Rankine's active pressure $\left(\mathrm{P}_{\mathrm{a}}\right)$ :

$$
P_{a}=K_{a} \gamma z-2 c^{\prime} \sqrt{K_{a}}
$$

Here, $\mathrm{c}^{\prime}$ is the cohesion. A reinforcement computation and arrangement is designed to satisfy the bending moment values and shear force magnitude of the system. The comparison of the calculated bending moments with the required moments is carried out to prove the accuracy of the reinforcement. Length of the reinforcement is adjusted in order to satisfy the stability of the junction points of the shelf configuration. To prevent failure at the joints of shelves, stability of reinforced concrete demand an assessment of the process that control the behavior of the shear forces and bending moments. The retaining wall is an important part of the transportation and geotechnical systems. The damages of retaining wall in an earthquake create difficulties to the traffic flow with huge economic loss of rescue work ( $\mathrm{Li}$ et al,2011).

\section{Case Study:-}

This study deals with the application of a new retaining system in order to reduce the weight of soil layers on the shelves more than a single shelf. A novel approach to providing external stability on retaining wall had come into existence to minimize earth pressure with the multiple pressure relief shelves. An application of multiple shelves is performed to eliminate the necessity of enlargement of the stem cross section. Instead of construct vertical wall 
terracing, the integrity of the retaining system was conserved and the problems due to the geometric constraints were eliminated.

A reinforced concrete cantilever wall with relief shelves is designed to retain fill to a height of 14.3 meters. The backfill behind the retaining wall has a dry unit weight of about $18 \mathrm{kN} / \mathrm{m}^{3}$ and shear strength parameters of $c^{\prime}=5$ and $\emptyset^{\prime}=40^{\circ}$. Additional features, such as the ground water height $\mathrm{H}_{\mathrm{w}}$ and surcharge load $\mathrm{q}$ are shown in Figure 1 as a typical cross-section with the maximum design wall height. A surcharge load of $17 \mathrm{kN} / \mathrm{m}^{2}$ was applied for traffic loading.

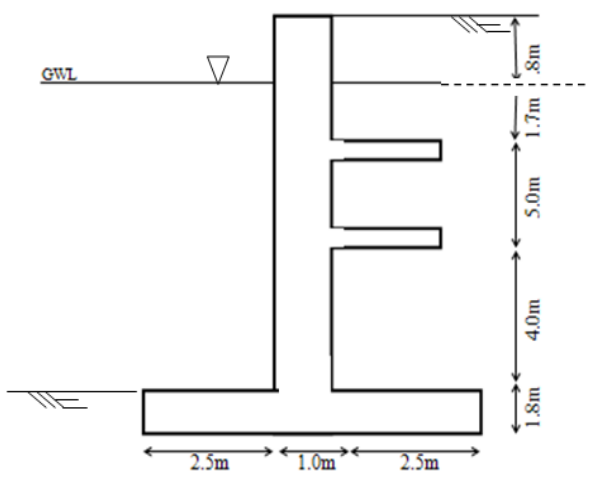

Fig. 1:- Retaining wall with multiple shelves.

The calculations of forces (total horizontal forces, $\mathrm{R}_{\mathrm{H}}$, total vertical forces, $\mathrm{R}_{\mathrm{V}}$ ) and moments (overturning moment, $\mathrm{M}_{\mathrm{H}}$, restoring moment, $\mathrm{M}_{\mathrm{V}}$ ) are set out in Table 1 .

Table 1 Factors of safety against sliding and overturning with forces and moments.

\begin{tabular}{|l|l|l|l|}
\hline Forces (t) & \multicolumn{2}{|l|}{ Moments (tm) } & \\
\hline $\mathrm{R}_{\mathrm{H}}$ & 21.75 & $\mathrm{M}_{\mathrm{H}}$ & 109.39 \\
\hline $\mathrm{R}_{\mathrm{V}}$ & 59.72 & $\mathrm{M}_{\mathrm{V}}$ & \\
\hline Factor of safety & 2.30 & & \\
\hline Sliding & 2.07 & & \\
\hline Overturning & 1.04 & & \\
\hline Eccentricity & \multicolumn{3}{|l|}{} \\
\hline
\end{tabular}

The required number of stem reinforcement until the first shelf was 3 whereas number of stem reinforcement was 2 for second shelf above the base slab. Figure 2 shows the elevation and bending moments of retaining wall divisions with shear forces.

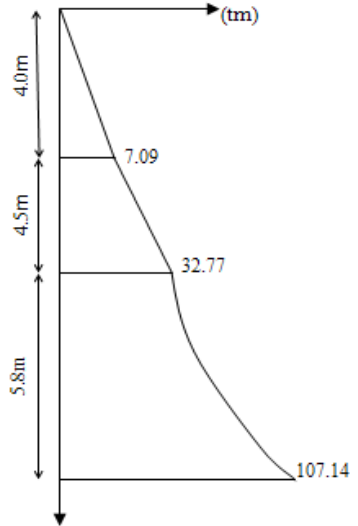

(a)

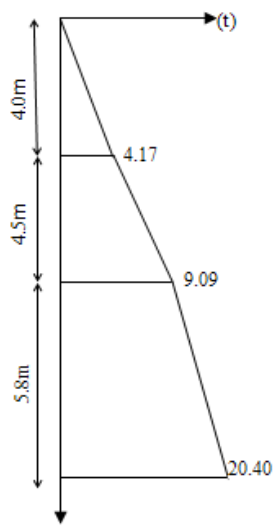

(b)

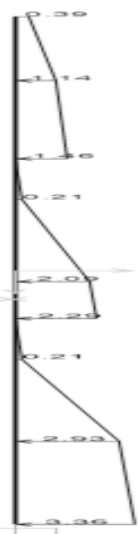

(c)

Fig. 2:- (a)Bending moments, (b) shear forces, (c) lateral pressures of stem part of wall 
The cross sections and reinforcement details of wall are summarized in Figure $3 \mathrm{a}, 3 \mathrm{~b}$ and $3 \mathrm{c}$. Within three vertical sections of wall (base section- $5.8 \mathrm{~m}$ long, middle section- $4.5 \mathrm{~m}$ and top section- $4.0 \mathrm{~m}$ ), the steel bars are placed in stepwise and three rows. Accordingly, number of steel bars and rows for unit-width wall $(100 \mathrm{~cm})$ are indicated as in Fig.3.

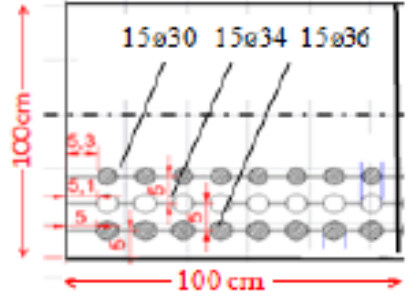

(a)

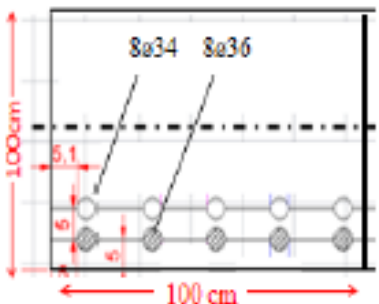

(b)

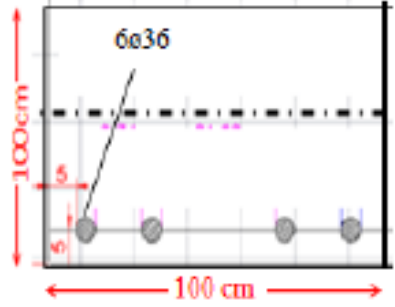

(c)

Fig. 3:- (a)Reinforcement of base section at $5.80 \mathrm{~m}$-long, (b) Reinforcement of middle section at $10.30 \mathrm{~m}$, (c) Reinforcement of top section at $14.30 \mathrm{~m}$-long

First row reinforcement continues through the entire retaining wall. In each transfer region of reinforcement was taken as a quarter of reinforcement length. Figure 4 is summarizes the theory of beam on elastic foundation.

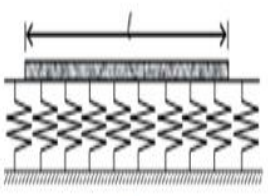

his

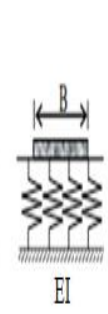

EI

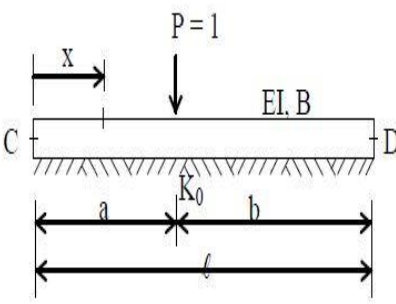

(b)

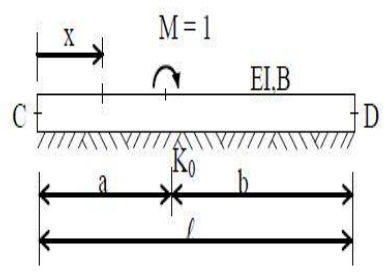

(c)

Fig. 4:- (a) Beam on elastic foundation, (b) Unit-concentrated loading on elastic foundation (c)Unit-bending moment loading on elastic foundation

Winkler assumes that reaction forces of the foundation are proportional at every point to the deflection of the beam at this point under applied external loads (Winkler,1876). The elasticity of the of foundation which follows the Hooke's law characterized by the force called the modulus of the foundation $K_{\mathrm{o}}$. Winkler's constant, $\mathrm{K}$ which includes the effect of the width of the beam and the characteristic of the system, $\lambda$ are described by the following equations:

$K=K_{0} B$

$\lambda=\sqrt[4]{\frac{K}{4 E I}}$

The equations of shear force and moment in accordance with particular integral of beam on elastic foundation equations of concentrated moment and concentrated load can be expressed respectively as in Equations 5-8 (Kameswara Rao,2011):

$$
\begin{aligned}
& M(x)_{M}=-M \delta_{M M}^{(x)} \\
& Q(x)_{M}=-\lambda \beta_{Q M}^{(x)}=-\frac{\lambda l}{l} M \beta_{Q M}^{(x)}=-M \delta_{Q M}^{(x)} \\
& M(x)_{P}=P L \frac{1}{\lambda l} \beta_{M P}^{(x)}=P l \delta_{M P}^{(x)} \\
& Q(x)_{P}=P \beta_{Q P}^{(x)}=P \delta_{Q P}^{(x)}
\end{aligned}
$$

Here, $\delta_{M M}^{(x)}, \delta_{Q M}^{(x)}, \delta_{M P}^{(x)}, \delta_{Q P}^{(x)}$ values can be taken fron charts and tables in practice (Kameswara Rao,2011). For using easy-use of functions and integral terms including complex terms, the influence lines are generally generated as seen in Figure $4 \mathrm{~b}$ and $4 \mathrm{c}$. Figure 5 depicted the beam on elastic foundation mechanism in this study. 


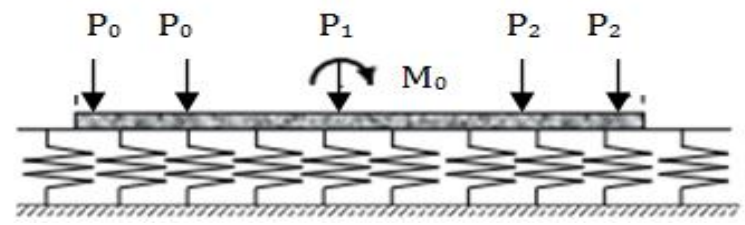

Fig. 5:- Beam on elastic foundation system of the retaining wall.

The computational model of a beam on an elastic foundation is often used to describe a lot of engineering problems and has application in geotechnics. In this study, an analytical solution of the problem of beam on elastic foundation was investigated bending moments and shear diagram were shown in Figure 6 and Figure 7. $\mathrm{P}_{0}$ and $\mathrm{P}_{2}$ represent respectively the water and water-soil concentrated loads on both cantilever parts of concrete base. $\mathrm{P}_{1}$ is denoted as concentrated load originated from vertical part of concrete wall. $\mathrm{M}_{0}$ is the bending moment at fixed support of the vertical part of RC wall which is assumed as cantilever beam and exposed to lateral active earth pressure. Sectional bending moments and shear forces of concrete base considered as beam on elastic soil are calculated by superposition of concentrated loads spaced at base and bending moment of vertical wall support placed at central point of base. Therefore, the bending moment and shear force diagrams required especially in RC design are plotted for both sides of concrete base of the vertical wall. RC design is carried out in accordance with Turkish Standarts on Reinforced Concrete Design of Building (Turkish Standards-500,2000).
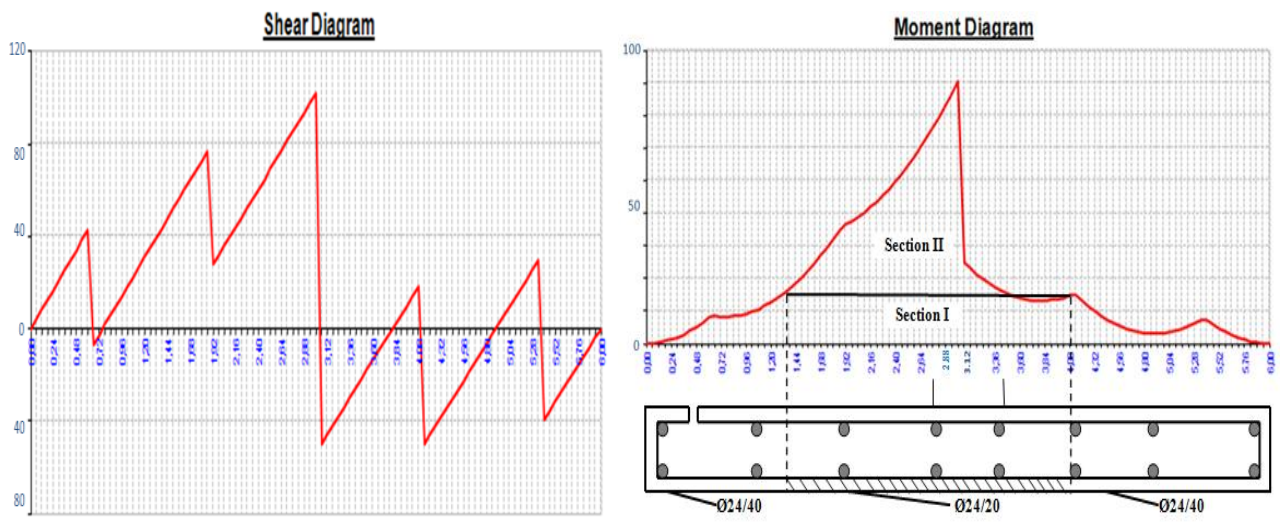

Fig. 6:- Shear and moment diagram of retaining wall as beam on elastic foundation.

In Figure 6, Section 1 considered as doubly reinforced rectangular section covers the $40 \mathrm{~cm}$-spaced steel bars $3 \# 24$ with the $600 \mathrm{~cm}$-long for the $100 \mathrm{~cm}$-width of base. In order to respond the maximum bending moment, the additional steel bars (more $3 \# 24$ with the $270 \mathrm{~cm}-\mathrm{long}$ ) are placed only at Section 2. At the intersection length of base, the steel bars to be applied are 6\#24. Base section where the support of vertical wall is located is therefore strengthened.

\section{Conclusion:-}

In this study, it is aimed that the lateral active earth pressure forces and their overturning moments can be decreased, the weight of double shelves and their protective moments can be increased, double reinforced rectangular section of base on elastic foundation can be equipped well and vertical steel bars in vertical retaining wall designed as cantilever can be placed by stepped and multiple rows reinforcement. Under these conditions, the required earth pressures, the overturning-protective moments and shear forces they causes, effect of elastic soil basement and reinforcement of vertical and horizontal rectangular wall sections are achieved. Results show that the proposed method can capture the displacements and bending moments of retaining wall more accurately than the retaining wall with single shelf. In this study, efforts were made to develop a multiple shelves system of retaining wall to satisfy successfully external and internal stability of the wall. The proposed method on special-designed RC retaining wall maximizes the friction capacity of the retaining system in presence of the multiple shelves. The purpose of this study is therefore realized by demonstrating the usage of multiple and elevated shelf on an elastically-founded retaining system with high backfill mass. 


\section{References:-}

1. Banerjee, S. P.,(1977), Soil behaviour and pressure on retaining structures with relief shelves., Indian Highways, pp.21-34

2. Farouk, H.(2015),Effectiveness of Using Shelves with Cantilever Retaining Walls, AEI Conference, 627-637, 2.

3. Jumikis, A.R. (1964),Mechanics of Soils, D. Van Nostrand Compan Inc, Princeton NJ.

4. Kip, F., Kumbasar, V. (1999), Problems on Soil Mechanics, Caglayan Publishing.

5. Li, J., Li, Z., Zhang, H. (2011), Post-earthquake emergency safety assessment of road retaining wall, ASCE, ICTIS: pp. 174-181.

6. Padhye, R.D.,Ullagaddi, (2011),P.B. Analysis of Retaining Wall with Pressure Relief shelf by Coulomb's method. Proceedings of Indian Geotechnical Conference Paper, No. K-106

7. Phatak, D.R., Patil, V.(1975), Effect of Relief Shelves on Earth Pressure, Institute of Engineers, (India) JournalCl, Vol. 55, $156-159$.

8. Chaudhury, P.R.,(1973), Design of Retaining Walls with relieving shelves, IRC Journal, 1973; Vol. 35, (2), pp. 289 - 325. Paper No. 295.

9. Teodoru,I.B.,(2009),Beams on Elastic Foundation:The Simplified Continuum Approach, Publicat deUniversita Tehnică,Gheorghe Asachi, Tomul LV (LIX), Fasc. 4, Buletınul Institutului Politechnic Din Iaşi

10. Winkler, E. (1867), Die Lehre Von Elasticitaet Und Festigkeit. 1st Edn., H. Dominicus, Prague

11. Kameswara Rao ,N.S.V.,(2011),Foundation Design: Theory and Practice, John Wiley \& Sons (Asia) Pte Ltd.

12. Karmvir Tiwari,K.,Kuppa,R.,(2014), Overview of Methods of Analysis of Beams on Elastic Foundation, IOSR Journal of Mechanical and Civil Engineering (IOSR-JMCE) Volume 11, Issue 5 Ver. VI , pp. 22-29

13. Janco,R.,2010, Solution Methods for Beam and Frames on Elastic Foundation Using the Finite Element Method,International Scientific Conference on Mechanical Structures and Foundation Eng., Ostrava

14. Turkish Standard TS-500,2000,Requirements for Design and Construction of Reinforced Concrete Structures, Institute of Turkish Standards, Necatibey Caddesi No.112 Bakanlıklar/ANKARA(in Turkish) 